\title{
Letters
}

\section{Polyarteritis nodosa associated with idiopathic pulmonary fibrosis: report of two cases}

SIR, An association between polyarteritis nodosa and idiopathic pulmonary fibrosis has been reported in only four cases. ${ }^{1-4}$ We describe two cases with histological evidence of this association.

\section{Case reports}

PATIENT NO 1

A 70 year old woman complained of cough and mild exertion dyspnoea during two years before admission. She presented with fever, asthenia, anorexia, weight loss, arthralgias, and worsening of her respiratory symptoms of three months' duration.

On physical examination the patient appeared chronically ill. Her temperature was $38.5^{\circ} \mathrm{C}$ and respiratory rate $26 /$ minute. Positive findings on examination included diffuse inspiratory crackles over the lower third of both lung fields. Laboratory data showed haemoglobin concentration $88 \mathrm{~g} / \mathrm{l}$, white cell count $11.72 \times 10^{9} / 1$ with a normal differential, and platelet count $525 \times 10^{9} / 1$. The erythrocyte sedimentation rate was $97 \mathrm{~mm} / \mathrm{h}$. Results of blood sugar, serum electrolytes, and liver studies were normal. Blood urea was $9.7 \mathrm{mmol} / \mathrm{l}$ and blood creatinine $279 \mu \mathrm{mol} / \mathrm{l}$. The urinary sediment was normal and the proteinuria 830 $\mathrm{mg} / 24$ hours. Serum immunoglobulins and serum complement were normal. Hepatitis B surface antigen and antibodies were negative. Latex test was positive at 1/80. Antinuclear antibodies and cryoglobulins were negative. Chest roentgenogram showed a diffuse reticulonodular infiltrative pattern in both lungs. Arterial blood gas analysis at room air showed partial pressure of oxygen $\left(\mathrm{PaO}_{2}\right) 7.6 \mathrm{kPa}$, partial arterial pressure of carbon dioxide $\left(\mathrm{PaCO}_{2}\right) 2.8 \mathrm{kPa}$, and $\mathrm{pH} \mathrm{7.41.} \mathrm{A} \mathrm{lung} \mathrm{gallium-67} \mathrm{citrate}$ scan showed an increased uptake in both lungs, suggesting areas of active inflammation. A bronchoscopic examination was normal and the transbronchial biopsy findings nonspecific. Investigations for bacteria, fungus, viruses, and mycobacteria were negative. An open lung biopsy was done two weeks after admission and histological examination disclosed a pulmonary fibrosis with no signs of vasculitis. Prednisone $1 \mathrm{mg} / \mathrm{kg} /$ day was then given. Over the next few days progressive renal failure became apparent requiring haemodialysis. The patient died with respiratory failure and fever suggesting a nosocomial pneumonia.

The necropsy showed evidence of a necrotising systemic vasculitis type polyarteritis nodosa, involving kidney, digestive tract, liver and gall bladder, spleen, genitourinary tract, skeletal muscle, peripheral nervous system, and bronchial arteries. The pulmonary arteries were not involved. An idiopathic diffuse interstitial pulmonary fibrosis and a pneumonia with Pseudomonas aeruginos positive lung cultures were found. Glomerulonephritis was̄ not present. Kidney and lung immunofluorescent studie $\bar{p}$ were negative.

PATIENT NO 2

A 46 year old woman was admitted to hospital after one year's history of pain in the legs and fever of one month'? duration. Two years earlier she had had a biopsy proved diagnosis of idiopathic pulmonary fibrosis. Her father brother, and niece had the same disease, suggesting familial idiopathic pulmonary fibrosis. She had been taking prednisone $8 \mathrm{mg}$ daily for two years.

On examination the patient appeared chronically ill: There was a livedo reticularis on both legs. BilateraP clubbing of the fingers was noted. Her temperature was $38^{\circ} \mathrm{C}$, pulse 100 beats/minute, and respirations $24 /$ minute? Her blood pressure was $130 / 80 \mathrm{mmHg}$. Heart and abdo윽 men were normal. Chest auscultation showed bilateraLbasal inspiratory crackles. Neurological examination was strongly suggestive of polyneuritis involving both legs. The ophthalmological examination and a Schirmer test wereo negative. Laboratory data showed haemoglobin concentra tion $102 \mathrm{~g} / \mathrm{l}$, white cell count $12 \cdot 37 \times 10^{9} / \mathrm{l}$, with a normato differential, and platelet count $967 \times 10^{9} / 1$. The erythroeteo sedimentation rate was $103 \mathrm{~mm} / \mathrm{h}$. Results of blood sugar: serum electrolytes, and liver function studies were nornfilo Blood urea was $3 \mathrm{mmol} / \mathrm{l}$ and blood creatinine $122 \mu \mathrm{mow} / \mathrm{t}$ The urine sediment and the proteinuria were normal $\bar{\partial}$ Arterial blood gases measured at room air showed $\mathrm{pH}$ 7.43; $\mathrm{PaCO}_{2} 4.4 \mathrm{kPa}$; and $\mathrm{Po}_{2} 8.0 \mathrm{kPa}$. The chestD roentgenogram showed a bilateral basal reticulonodula pattern. A lung gallium-67 citrate scan showed an increased uptake in both lungs. A bronchoscopic examina tion was normal. Bronchoalveolar lavage showed 530 cells? macrophages $78 \%$, neutrophils $16 \%$, and lymphocyte? $6 \%$. Serum immunoglobulins and serum complement were్ normal. Hepatitis B surface antigen and antibodies were negative. Latex test was positive at $1 / 80$. Tests foํㅡㄴ antinuclear antibodies, anti-DNA, extractable nucleạִ. antigens, anti-RNP, anti-Ro, anti-La, and cryoglobulins were negative. Electromyographic findings were indicative of a multiple mononeuropathy. Biopsy of skin, muscle and sural nerve was done. The histology showed a mono nuclear infiltration with fibrinoid necrosis involving smalp and medium sized muscular arteries. Treatment with cyclophosphamide was started at $2 \mathrm{mg} / \mathrm{kg}$ daily and tho prednisone was increased to $1 \mathrm{mg} / \mathrm{kg}$ daily.

One year after the diagnosis of polyarteritis nodosa the vasculitis remains controlled, but the idiopathic pulmonary fibrosis despite continued prednisone and cyclophospha $\sigma$ mide treatment has not improved and the patient needs continuous oxygen treatment at home.

\section{Discussion}

Excellent reviews dealing with polyarteritis nodosa and idiopathic pulmonary fibrosis do not comment on arn 
association between the diseases. ${ }^{5} 6$ This association has been described previously in non-English publications, however. ${ }^{1-4}$

There are some diseases which could explain both the pulmonary and systemic involvement similar to the one seen in these patients, ${ }^{7-9}$ but these were reasonably ruled out in our patients on the basis of clinical features, special studies, and histological findings.

As immunological phenomena play an important part in polyarteritis nodosa and idiopathic pulmonary fibrosis a common immunopathological link between the two diseases may exist. It is more probable, however, in view of the rarity of the association that the joint occurrence of these two uncommon diseases is simply coincidental. Further reports of new cases might help to determine whether this association is real or not.

\section{Divisions of Internal \\ Medicine and Pulmonary \\ Diseases,}

Bellvitge Hospital,

University of Barcelona, 08907 L'Hospitalet,

Barcelona, Spain

*Correspondence to Dr Jordi Carratalá, Gran Via 1075, $1^{\circ} 3^{\mathrm{a}} \mathrm{A}$. 08020 Barcelona, Spain.

\section{References}

1 Gherman G, Niculescu I, Serban A L, Caluser I. Uber einen Fall von Periarteritis nodosa mit interstitieller, difusser Lungenfibrose und parietaler fibröser Endokarditis. Z Gesamte Inn Med 1963; 18: 827-9.

2 Turiaf J, Basset F, Battesti J P. Fibrose interstitielle diffuse de la périartérite noueuse. Bulletins et Memoires de la Societe Medicale des Hopitaux de Paris 1965: 116: 1149-60.

3 De Biaso R, Stanisic M, Reutter F W. Diffuse lungenfibrose bei Panarteritis nodosa. Schweiz Med Wochenschr 1973; 103: 1540-3.

4 Accarino A, Richart C. Lucas A. Pedreira J D. Alomar C. Neumonía intersticial linfoidea y periarteritis nodosa. Rev Clin Esp 1983; 171: 363-4.

5 Cupps T A. Fauci A S. The vasculitides. Philadelphia: Saunders. 1981: 26-49.

6 Crystal R G. Fulmer J D, Roberts W C. Moss M L. Line B R. Reynolds H Y. Idiopathic pulmonary fibrosis. Clinical, histologic, radiographic, physiologic. scintigraphic. cytologic, and biochemical aspects. Ann Intern Med 1976; 85: 769-88.

7 Hunninghake G W. Fauci A S. Pulmonary involvement in the collagen vascular diseases. Am Rev Respir Dis 1979; 119: 471-503.

8 Fulmer J D. Kaltreider H B. The pulmonary vasculitides. Chest 1982; 82: 615-24.

9 Leavitt R Y, Fauci A S. Pulmonary vasculitis. Am Rev Respir Dis 1986; 134: 149-66.

\section{Autonomic dysfunction in systemic sclerosis: the site of damage}

SIR, In considering the site of damage underlying abnormal autonomic function in their patients with systemic sclerosis, Klimiuk and colleagues' highlighted the lack of evidence for the presence of somatic neuropathy in the four cases reported by Sonnex and coworkers. - As we have emphasised elsewhere ${ }^{3}$ there are several reasons why such signs may not have been detected in that study. Firstly. clinical assessment was limited to the legs and to the use of vibration threshold. Secondly, nerve conduction studies were performed in only one case. (Details of these studies were, moreover, not given.) Finally, and perhaps not least, morbid involvement of peripheral nerves in systemic sclerosis may be focal. ${ }^{4}$

After the article by Klimiuk and colleagues had been accepted by the Annals we published a report of the results of cardiovascular autonomic tests in eight unselected cases of systemic sclerosis. ${ }^{3}$ The six patients who had abnormal values for one or more of the five tests all had clinical $(n=6)$ or electrophysiological $(n=5)$ evidence of somatic neuropathy also. Of the sites thereby sampled, the sural nerve was involved in every instance, the median motor nerve in two instances, and the median sensory and peroneal nerves in one instance each. Abnormalities were consistent with axonal degeneration. ${ }^{45}$ This type of pathological change occurs in angiopathic neuropathy, ${ }^{6}$ while arterial damage is a characteristic feature of systemic sclerosis. $^{\text {? }}$

Having regard to the above circumstances, we believe it is premature to imply, as Klimiuk and colleagues ${ }^{1}$ did, that the neuroanatomical basis of autonomic dysfunction in systemic sclerosis differs essentially from that in other connective tissue diseases because in those conditions a somatic neuropathy is usually demonstrable. ${ }^{89}$ The possibility that damage is located more proximally to the effector site is nonetheless an intriguing suggestion and we await with interest the outcome of the authors' studies. Meanwhile, we wonder whether their next report will also include an assessment of peripheral nerve function.

Department of Internal Medicine, University of the Witwatersrand. and the IJohannesburg Hospital, Johannesburg, South Africa, and the

2East Surrey Hospital,

Redhill, Surrey

*Correspondence to Dr R F Gledhill. Little Roke. Bouveric Road. Chipstead, Coulsdon. Surrey CR3 3LX.

\section{References}

1 Klimiuk P S. Taylor L. Baker R D, Jayson M I V. Autonomic neuropathy in systemic sclerosis. Ann Rheum Dis 1988: 47: $542-5$.

2 Sonnex C. Paice E. Whitc A G. Autonomic neuropathy in systemic sclerosis: a case report and evaluation of six patients. Ann Rheum Dis 1986: 45: 957-60.

3 Dessein P H M C. Gledhill R F. More on autonomic neuropathy in systemic sclerosis. Ann Rheum Dis 1988; 47: 261-3.

4 Di Trapani G. Tulli A, La Cara A, Laurienzo P. Mazza S. David P. Peripheral neuropathy in course of progressive systemic sclerosis. Light and ultrastructural study. Acta Neuropathol (Berl) 1986: 72: 103-10.

5 Kimura J. Nerve conduction studies and electromyography. In: Dyck P J. Thomas P K. Lambert E H. Bunge R. eds. Peripheral neuropathy. 2nd ed. Philadelphia: Saunders. 1984: 919-66. 